\title{
SUPEROVULATION FOLLOWING OVARIAN X-IRRADIATION
}

\author{
ANITA M. MANDL \\ Department of Anatomy, University of Birmingham
}

(Received 8th May 1964)

Summary. Direct irradiation of one ovary with 315 or $630 \mathrm{r}$ was followed by a reduction in the number of eggs shed on the irradiated side, and compensatory overactivity by the unirradiated ovary. Unilateral irradiation with $157 \mathrm{r}$, or exposure of one ovary to air (involving surgical handling) induced slight superovulation on the treated side. The total number of eggs shed by both ovaries was highest in unilaterally irradiated animals whose second ovary was exposed to air; slightly fewer eggs were shed by those whose second ovary was left untouched; and the least number was recorded for control animals one of whose ovaries was exposed to air (the other left untouched). The degree of superovulation was less pronounced than that recorded for rats irradiated bilaterally with $157 \mathrm{r}$ (cf. Mandl, 1963a). The results suggest that the superovulatory effect of irradiation is primarily due to 'non-specific' damage to the ovary, and is mediated by a reduction in the number of pre-existing large Graafian follicles undergoing atresia.

Newly-formed corpora lutea in unilaterally irradiated ovaries were consistently smaller than those in non-irradiated ovaries. The effect is apparently due to radiation-induced damage sustained by the granulosa cells before ovulation.

In animals irradiated at metoestrus and which mated the following oestrus, the number of unfertilized eggs was higher on the irradiated than on the unirradiated side. Even so, the proportion of unfertilized eggs on the unirradiated side was higher than in normal animals.

The proportion of tubal eggs showing morphological abnormalities was very low. By the time of autopsy, 9 to $10 \mathrm{hr}$ after expected ovulation, pronuclear development had not proceeded as far in unilaterally irradiated as in unirradiated animals. The effect was particularly marked on the unirradiated side. Unilateral irradiation appears to disturb the developmental synchronization of oocytes between the two ovaries, and may induce the premature rupture of a small number of follicles.

\section{INTRODUCTION}

Numerous clinicians have claimed that exposure to 'low' doses of X-rays is followed by ovarian stimulation or 'excitation' (e.g. Fraenkel, 1914; Rubin, 
1926; Kaplan, 1948, 1958; Fullenlove, Haman \& Williams, 1956; Morgan \& Reyes, 1957; Caballero \& Hurtado, 1963). The treatment, sometimes combined with irradiation of the pituitary (see Asherman, 1952), is said to regulate menstruation in sterile women, many of whom subsequently become pregnant. This method of treating menstrual disorders and infertility has been repeatedly criticized, and its scientific basis questioned (e.g. Lacassagne, Duplan, Marcovich \& Raynaud, 1962; Rugh, 1964).

Experiments on laboratory animals have yielded inconsistent results. Mandel \& Grisewood (1934) and Mandel (1935) irradiated female rats aged 7 or 10 days, and again 1 week later ( 540 to $1240 \mathrm{r}$ ). As judged by the rupture of the vaginal closure membrane, puberty occurred earlier in the irradiated rats; the effect is said to be mediated by radiation-induced stimulation of follicular growth. Beaumont (1962a) repeated this experiment, and reported that the age at which the vagina opened was the same in irradiated and control rats. Moreover, the treated animals had smaller ovaries and uteri than their controls. Irradiation with lower doses of X-rays during foetal life (Beaumont, 1962b), or higher levels at 18 to 29 days after birth (Mandl \& Zuckerman, 1961), was similarly followed by deleterious rather than stimulating effects upon the functional capacity of the ovaries.

Sladić-Simić, Živković, Pavić \& Martinovitch (1963) have recently reported that whole-body irradiation of 8-day-old rats with 50 and $100 \mathrm{r}$ is followed by follicular stimulation. The effect was significant in rats killed 9 days after irradiation, but 1 week later it was much reduced $(50 \mathrm{r})$ or reversed $(100 \mathrm{r})$. Animals killed 34 to 42 days after treatment possessed consistently fewer growing follicles than the controls; yet after puberty they gave birth to significantly larger first litters. As judged by the number of corpora lutea (Martinovitch, personal communication), the effect was due to superovulation. These findings thus indicate that irradiation may exert a superovulatory effect in young rats for as long as 6 weeks, a period far exceeding that during which it occurs in adult mice (Russell \& Russell, 1956, see below). Peters \& Levy (1963), who irradiated mice with $20 \mathrm{r}$ on the 7th and 14th days after birth, observed a reduction, rather than any increase, in the size of the first litters.

A strictly temporary 'excitatory' effect of irradiation was reported by Russell \& Russell $(1954,1956)$. Adult female mice were given whole-body irradiation with $400 \mathrm{r}$, and then housed with males. Numbers of corpora lutea of pregnancy were counted at different intervals between irradiation and fertilization (see Russell \& Russell, 1956). As compared with control numbers, the means in irradiated mice rose to a peak of $142 \%$ at $1 \frac{1}{2}$ to $4 \frac{1}{2}$ days, and subsequently declined below control values at over 2 weeks.

An even greater degree of superovulation has been observed in adult rats (Pozhidaev, 1960; Mandl, 1963a; Hahn \& Morales, 1964). Pozhidaev does not specify the period between irradiation and fertile mating, but he reports that following whole-body or localized irradiation with $600 \mathrm{r}$, the mean numbers of corpora lutea rise by about $50 \%$. In Mandl's (1963a) study, the superovulatory effect was most pronounced following ovarian irradiation with 78 to $157 \mathrm{r}$ or 157 to $315 \mathrm{r}$ (intervals between irradiation and mating $<24 \mathrm{hr}$ and 5 to 9 days, respectively). Hahn \& Morales (1964) clearly demonstrate that the degree of 
superovulation depends on the phase of the oestrous cycle at the time of irradiation. The largest number of corpora lutea (about twice normal) occurred in animals exposed to whole-body irradiation $(400 \mathrm{r})$ at metoestrus, some $3 \frac{1}{2}$ to $4 \frac{1}{2}$ days before ovulation and fertile mating. The number of implantation sites was also significantly higher than in unirradiated rats, particularly in animals treated $2 \frac{1}{2}$ to $3 \frac{1}{2}$ days before mating.

Radiation-induced superovulation may be mediated by two different mechanisms: either a direct effect on the ovary (specific or unspecific), or an indirect effect via the pituitary. The possibility that it results from a direct activation of the pituitary, or hormonal imbalance caused by changes in other endocrine glands, is ruled out by the results of localized irradiation (e.g. Pozhidaev, 1960; Mandl, 1963a). An obvious way of differentiating between a direct and indirect mode of action is to perform unilateral ovarian irradiation, and compare the effect upon the two ovaries. Pozhidaev (1960) has done so, and observed that the number of corpora lutea of pregnancy was significantly higher on the unirradiated side than in that exposed to $600 \mathrm{r}$. The same effect was observed whether one ovary was irradiated while the rest of the body was shielded, or whether one ovary was protected while the rest of the body was irradiated. There was no significant difference between the number of corpora lutea in unilaterally irradiated ovaries and the mean for unirradiated controls.

Pozhidaev's (1960) results thus clearly demonstrate that unilateral irradiation is followed by superovulation on the unirradiated side, the stimulus ('distress signal') emanating from the irradiated gland. This stimulus may take at least two different forms. First, a reduction in the ability of the irradiated ovary to take up its share of gonadotrophin, resulting in more gonadotrophin being available to the unirradiated ovary (see Bruzzone, Lipschutz \& Niedmann, 1952; Falconer, Edwards, Fowler \& Roberts, 1961). Second, some change in the irradiated ovary which leads to an excessive release of gonadotrophin, to which the unirradiated ovary is the more competent to respond.

The present experiment was undertaken in order to discover (i) whether unilateral irradiation with doses of less than $600 \mathrm{r}$ is followed by superovulation in the contralateral ovary; (ii) the extent to which the effect is specific for radiation-induced changes in one ovary; and (iii) whether superovulation is mediated by growth of excessive numbers of follicles or the rupture of some which would normally degenerate at advanced stages of development.

\section{MATERIALS AND METHODS}

ANIMALS

One hundred and sixteen virgin rats, derived from thirty-four litter-groups and belonging to the Birmingham colony, were used. At the start of the experiment, their ages ranged from $2 \frac{1}{2}$ to 8 months.

The first thirty-six animals were used before a light-controlled room was available. They were kept under normal laboratory conditions (natural daylight). The remaining eighty rats were housed in a room illuminated between $6 \mathrm{a} . \mathrm{m}$. and 6 p.m. (complete darkness: 6 p.m. to 6 a.m.) for at least a fortnight before being subjected to irradiation or control-operation. 


\section{ARRANGEMENT OF EXPERIMENTS}

In a preliminary experiment, thirty-six rats (nine litter-groups) were unilaterally irradiated with 630,315 or $157 \mathrm{r}$. The second ovary was exposed to air (Treatment I: seventeen animals) or left untouched (Treatment II: nineteen animals). Vaginal smears were taken for a few days before irradiation. As soon as the animals recovered consciousness, sixteen of them were housed with males of proven fertility. The females were killed at their first post-operative oestrus (in two cases, at pro-oestrus), irrespective of whether or not they had access to a male, or mated. The interval between irradiation and autopsy ranged from 1 to 6 days.

The second group of animals (eighty, derived from twenty-five litters) were operated on during the day of metoestrus. Thirty-four were unilaterally irradiated with $157 \mathrm{r}$, the second ovary being exposed to air (Treatment I). Thirty were similarly treated, but their second ovary was left untouched (Treatment II). In the remaining sixteen, one ovary was exposed to air while the second was left untouched (Treatment III). Fifty-three animals (thirty-seven irradiated; sixteen non-irradiated) were housed with males of proven fertility after operation. All the animals that mated were killed during the morning following the appearance of spermatozoa in their vaginal smears. The rest were killed on the day of their first post-operative oestrus or metoestrus. The interval between treatment and autopsy varied between 3 and 5 days ( 7 and 8 days in two cases; see below).

The numbers of animals receiving different treatments are summarized in Table 1. Four animals were excluded from further study due to the irregularity of their oestrous cycle after irradiation: two showed prolonged cornification, and the other two prolonged dioestrus.

\section{$X$-irradiation}

EXPERIMENTAL PROCEDURES

The animals were anaesthetized by means of tribromoethanol ('Avertin'). One ovary was exteriorized and irradiated directly, the rest of the body being screened by lead (see Mandl \& Zuckerman, 1956). A superficial X-irradiation apparatus, set at $100 \mathrm{kV}$ and $5 \mathrm{~mA}$ was used. No filters were inserted, and the dose rate at the ovary was $430 \mathrm{r} / \mathrm{min}$ (see Mandl, 1959). Immediately after exposure, the ovary was replaced in the abdominal cavity and the incision closed.

\section{Exposure to air}

The ovary was exteriorized as if it were to be irradiated, and placed on top of the lead shield normally used during ovarian irradiation. It was exposed to air for 1 to $3 \mathrm{~min}$ and then replaced in the abdominal cavity. The incision was closed in the usual way.

\section{Autopsy}

The animals were weighed and then killed by means of chloroform vapour. The ovaries were dissected free from adjacent tissue in only the first thirty-six animals. In the remaining eighty, each ovary was fixed separately, still enclosed in its bursa and attached to its Fallopian tube. 


\section{Histology}

Each ovary (with its adnexa, where fixed) was sectioned serially at 5 or $7 \mu$. The sections were stained with Weigert's iron haematoxylin and lightly counter-stained with 'chromotrop 2R'.

All ovaries were first examined for signs of recent ovulation or presence of pre-ovulatory follicles. Serial sections were then scanned, and counts made of the numbers of freshly-formed corpora lutea (i.e. ruptured follicles; in the few animals killed at metoestrus, corpora lutea aged about 1.5 days). In the course of this procedure, the chromosomal configuration of the pre-ovulatory follicles was recorded. Large follicles enclosing atretic oocytes were excluded.

In animals of the second group which had recently ovulated, the serially sectioned Fallopian tubes were examined and the number of tubal eggs counted. Each tubal egg was examined under an oil-immersion objective for morphological abnormalities and signs of fertilization. If the number of freshly-formed corpora lutea in any specimen exceeded the recorded number of tubal eggs, the whole set of serial sections was thoroughly searched for the 'missing' egg(s).

With a few exceptions (ovaries of animals irradiated with 315 or $630 \mathrm{r}$ not containing ruptured follicles), the serial sections were projected on to paper at a magnification of $\times 58$ or $\times 62$, and the outlines of all recently formed corpora lutea and pre-ovulatory follicles drawn. This procedure served as a further check on the initial counts. The volume of each recent corpus luteum was then determined separately from measurements of the two maximum diameters at right angles (see Mandl, 1954). The mean maximum diameter of pre-ovulatory follicles was assessed as previously described (Mandl \& Zuckerman, 1952). Follicles enclosing atretic oocytes were again excluded.

\section{RESULTS}

VAGINAL SMEARS

Normal cyclical changes were observed in the vaginal smears of 112 rats (Table 1). The four animals whose oestrous cycle was disturbed had all been unilaterally irradiated.

Sixteen animals were killed shortly before ovulation, as judged by ovarian histology. Of these, the vaginal smear of thirteen was typically oestrous, and one metoestrous; the remaining two rats were killed at pro-oestrus (Table 1). In fourteen animals, therefore, the normal synchronization between the ovarian and the vaginal cycle was disturbed. None of the control animals failed to ovulate at the expected time.

\section{MATING BEHAVIOUR}

Of the sixty-nine females housed with a male, fifty mated during the first oestrus. The proportion that did so was of the same order for unilaterally irradiated $(74 \%)$ and unirradiated animals $(69 \%$; Table 1$)$.

\section{0 and $315 r$}

\section{QUANTITATIVE STUDY OF OVARIAN HISTOLOGY}

The exposure of one ovary to either 630 or $315 \mathrm{r}$ was followed by a reduction in the number of freshly-formed corpora lutea (and pre-ovulatory follicles) on $\mathrm{D}^{*}$ 


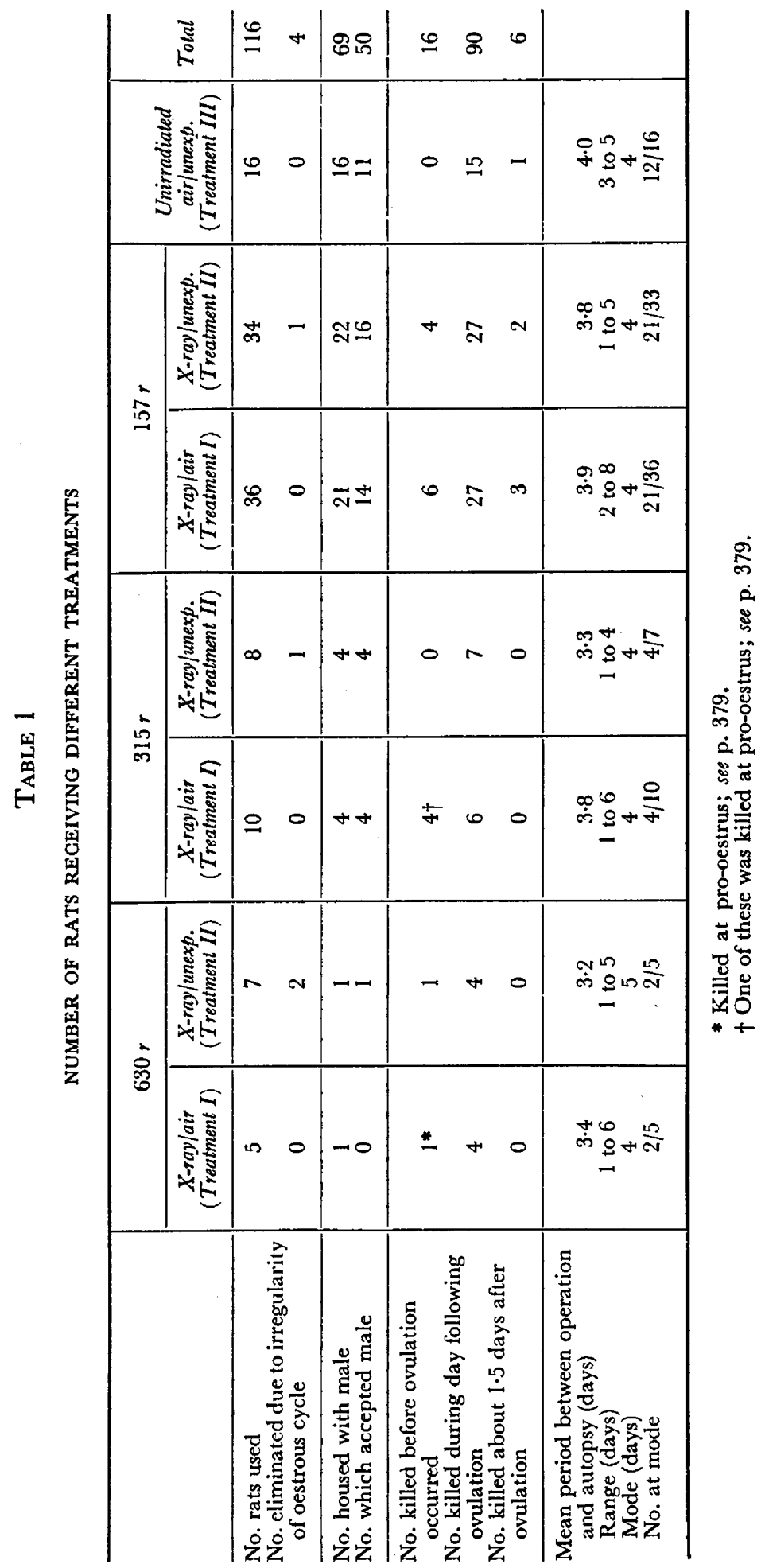


the irradiated side. The contralateral ovary apparently underwent some degree of compensatory overactivity during the brief post-operative period. As a result, the total number of eggs shed (or pre-ovulatory follicles) was within normal limits (Table 2).

The mean volume of freshly-formed corpora lutea was considerably lower in the irradiated ovaries than in their fellows (Table 2).

These observations clearly indicate that doses of 315 and $630 \mathrm{r}$, far from inducing superovulation on the irradiated side, exert the opposite effect.

TABLE 2

EFFECT OF UNILATERAL X-IRRADIATION WITH 630 AND $315 \mathrm{r}$ UPON FOLLICULAR GROWTH AND RUPTURE

\begin{tabular}{|c|c|c|c|}
\hline$\cdot$ & $\begin{array}{l}\text { Mean No. pre- } \\
\quad \text { ovulatory } \\
\text { follicles }\end{array}$ & $\begin{array}{l}\text { Mean No. } \\
\text { freshly-formed } \\
\text { corpora lutea }\end{array}$ & $\begin{array}{c}\text { Mean vol. }\left(\times 10^{-3} \mathrm{~mm}^{3}\right) \\
\text { freshly-formed } \\
\text { corpora lutea }\end{array}$ \\
\hline $\begin{array}{l}630 \mathrm{r} \text {, Treatment I } \\
\text { Irradiated ovary } \\
\text { Ovary exposed to air } \\
\text { Both ovaries }\end{array}$ & $\begin{array}{l}0 \\
8 \\
8(1)\end{array}$ & $\begin{array}{l}5 \cdot 25 \\
7 \cdot 25 \\
12 \cdot 5(4)\end{array}$ & $\begin{array}{l}119 \\
231 \\
185(4)\end{array}$ \\
\hline $\begin{array}{l}630 \mathrm{r} \text {, Treatment II } \\
\text { Irradiated ovary } \\
\text { Ovary unexposed } \\
\text { Both ovaries }\end{array}$ & $\begin{array}{l}0 \\
11 \\
11\end{array}$ & $\begin{array}{l}4 \cdot 50 \\
8 \cdot 00 \\
12 \cdot 5(4)\end{array}$ & $\begin{array}{l}149 \\
235 \\
216(4)\end{array}$ \\
\hline $\begin{array}{l}315 \mathbf{r}, \text { Treatment I } \\
\text { Irradiated ovary } \\
\text { Ovary exposed to air } \\
\text { Both ovaries }\end{array}$ & $\begin{array}{l}4 \cdot 75 \\
7 \cdot 25 \\
12 \cdot 0(4)\end{array}$ & $\begin{array}{l}4 \cdot 17 \\
7 \cdot 33 \\
11 \cdot 5 \quad(6)\end{array}$ & $\begin{array}{l}106 \\
180 \\
153(6)\end{array}$ \\
\hline $\begin{array}{l}315 \mathrm{r}, \text { Treatment II } \\
\text { Irradiated ovary } \\
\text { Ovary unexposed } \\
\text { Both ovaries }\end{array}$ & E & $\begin{array}{l}4 \cdot 14 \\
7 \cdot 71 \\
11.9 \quad(7)\end{array}$ & $\begin{array}{l}140 \\
209 \\
183(7)\end{array}$ \\
\hline
\end{tabular}

The figures in parentheses indicate the numbers of rats used.

$157 r$

Numbers of freshly-formed corpora lutea and pre-ovulatory follicles. Fifty-four unilaterally irradiated and fifteen non-irradiated controls ovulated shortly before autopsy. The mean numbers of freshly-formed corpora lutea (marked A) and their standard errors are shown in Table 3. As judged by $\chi^{2}$ and paired $t$-tests, the differences between the two ovaries are not statistically significant for any of the three treatment-groups. The variance between different rats receiving the same treatment is higher than that between the two ovaries of the same individual. The numbers of ruptured follicles in the two ovaries are negatively correlated (Text-fig. 1). The correlation was significant for Treatment-groups I and III; it was also significant for Treatment-group II if two exceptional animals (see below) are excluded from the analysis. This observation clearly indicates that the total number of eggs shed was reasonably constant, a low number on one side being associated with a relatively high number on the other (see Falconer et al., 1961; McLaren, 1963a). Although the differences between the two ovaries failed to reach statistical significance, there was a consistent trend for the numbers of new corpora lutea to be higher on the irradiated than the air-exposed or untouched side (110 and 107\%, respectively); a difference of the 
A. M. Mandl

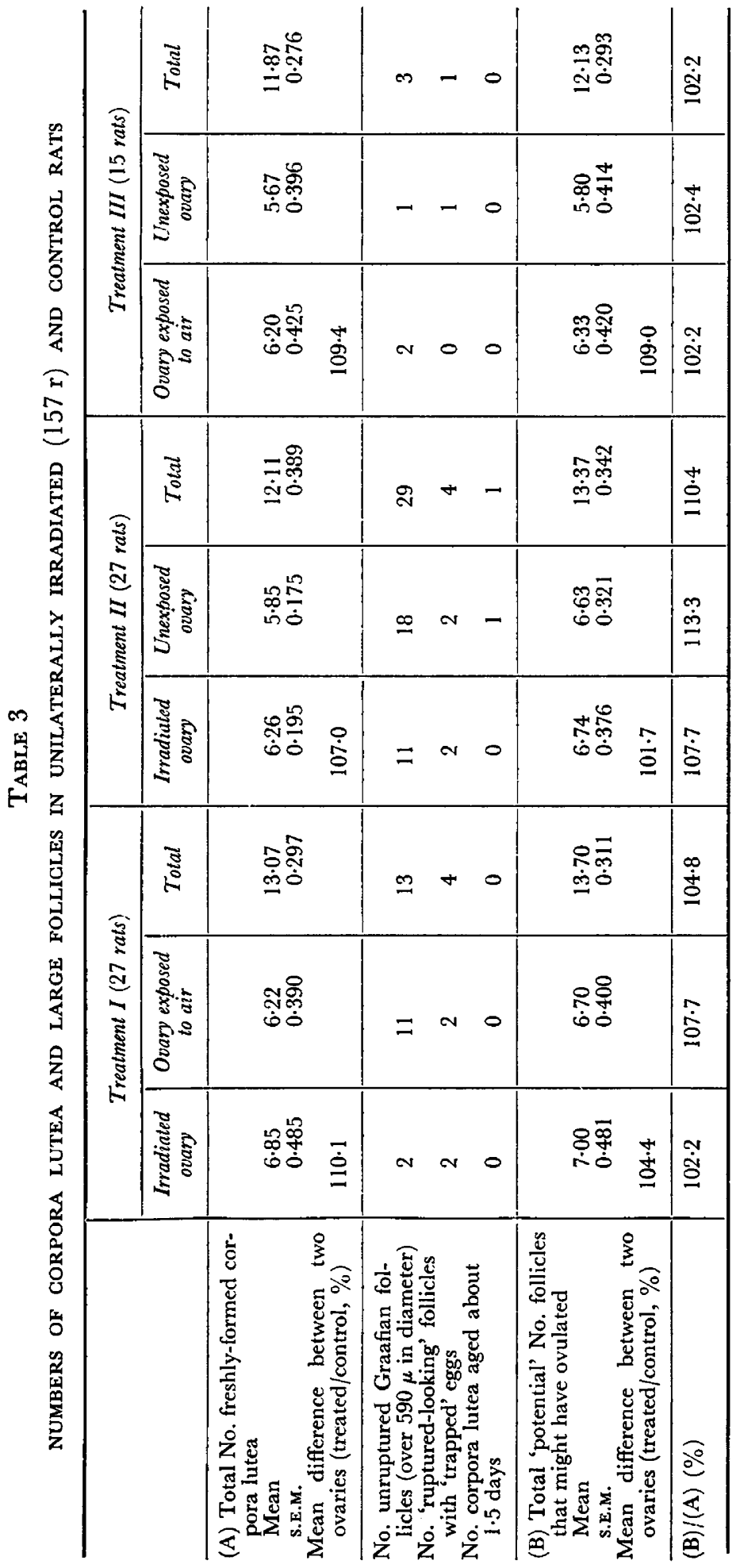


same order (109\%) was found between air-exposed and untouched ovaries of the controls (Table 3).

The total number of eggs shed by unilaterally irradiated animals tended to be higher than that shed by the unirradiated controls (Text-fig. 2). The mean total number for Treatment-group II rises from $12.11 \pm 0.389$ to $12.88 \pm 0.339$ if the two exceptional animals (see below) are excluded. The difference between the latter and that for non-irradiated controls is $8.5 \%$. The non-irradiated controls apparently shed slightly more eggs (mean $11.87 \pm 0.276$ ) than do unoperated

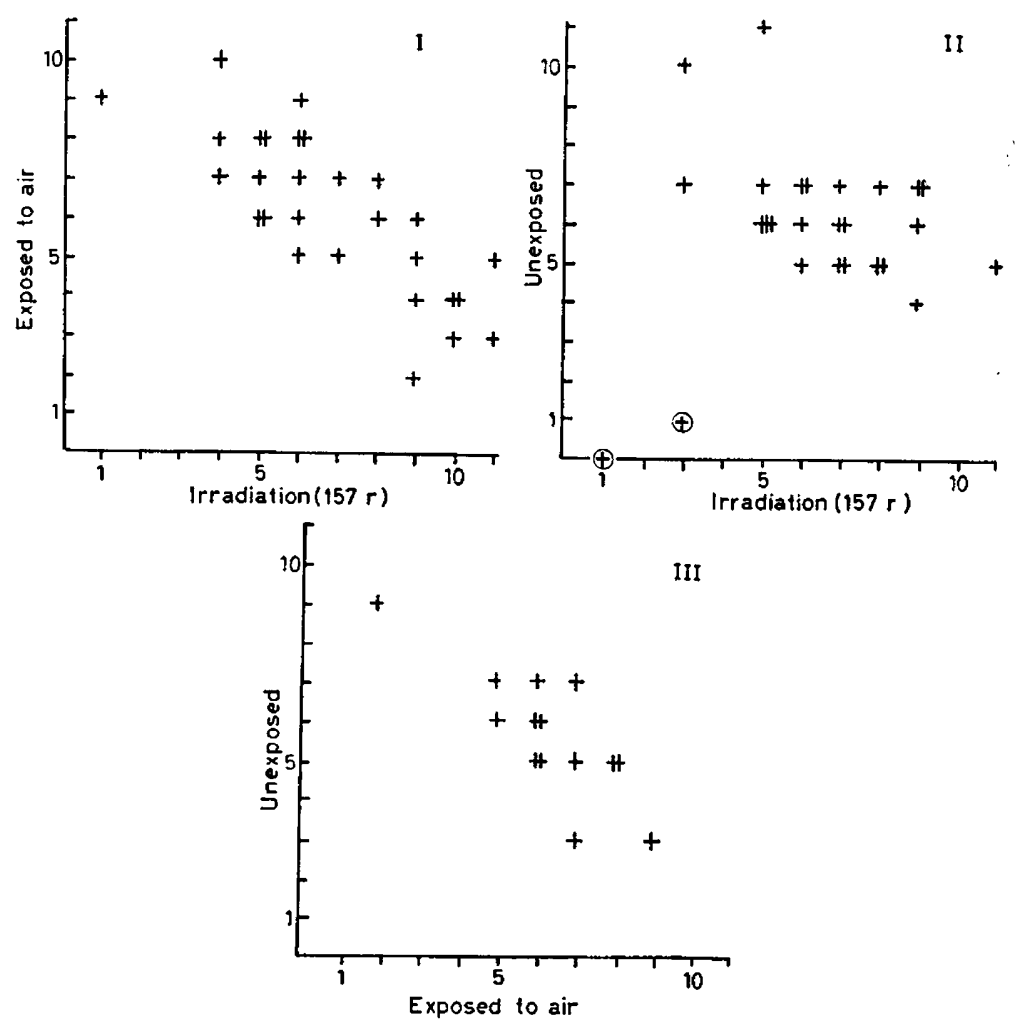

Text-FIG. 1. Distribution of freshly-formed corpora lutea between sides in Treatmentgroups I (unilateral irradiation; second ovary exposed to air), II (unilateral irradiation; second ovary untouched) and III (one ovary exposed to air; second untouched). $\oplus$ Data for two exceptional animals in Treatment-group II; see p. 381.

female rats of the same strain (mean for forty-three rats used in previous experiment: $11 \cdot 44 \pm 0 \cdot 283$; Text-fig. 3 ). Due to high variability between animals, and the relatively small numbers of rats used, none of these differences is statistically significant; but there is clearly a pattern of response which, because of its consistency, can hardly be disregarded.

The ovaries of two animals (both in Treatment-group II) contained both ruptured and unruptured follicles. In one pair, there were fourteen Graafian follicles and one ruptured follicle; in the other, ten Graafian follicles and four ruptured follicles. Four of the five newly-formed corpora lutea were on the 


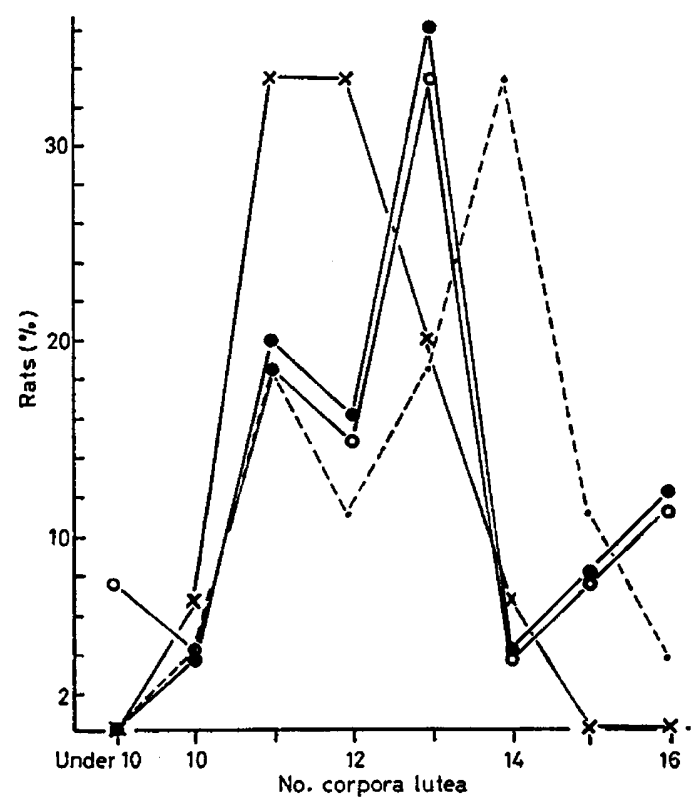

TEXT-FIG. 2. Frequency distribution of numbers of freshly-formed corpora lutea. . . . - Treatment-group I; O, Treatment-group II (all twenty-seven animals); 0 , Treatmentgroup II (excluding two exceptional rats, see p. 383); $\times$, Treatment-group III.

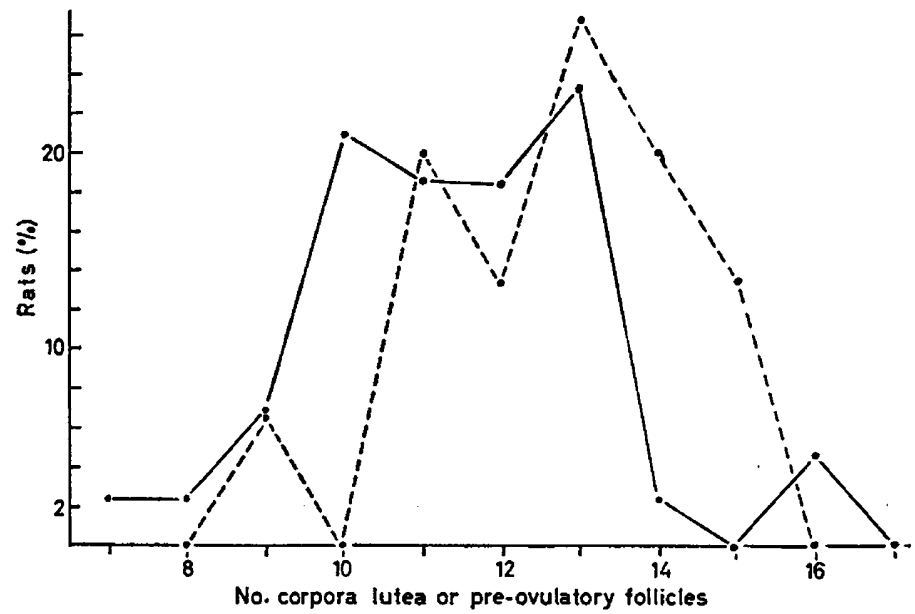

TEXT-FIG. 3. Frequency distribution of numbers of freshly-formed corpora lutea( and pre-ovulatory follicles (-..-) in unirradiated ovaries derived from rats of the same strain. Corpora lutea : mean for forty-three rats, $11 \cdot 44 \pm 0.283$; pre-ovulatory follicles past the stage of chromatin mass (see Mandl, 1963b): mean for fifteen rats, $12.67 \pm$ 0.432 . 
irradiated side. Some of the twenty-four pre-ovulatory oocytes were still in the late diplotene phase, while others were either at first or second metaphase, and none at intermediate stages (e.g. chromatin mass, prometaphase). It should be noted that normally, pre-ovulatory nuclear changes within a pair of ovaries are closely synchronized (see Mandl, 1963b).

Sixteen other ovaries, both irradiated and unirradiated, contained either one or two (but never more) large Graafian follicles enclosing an apparently normal oocyte. In general, the irradiated ovaries contained fewer unruptured follicles than did their unirradiated fellows (Table 3).

In the course of matching the counts of freshly-formed corpora lutea with those of tubal eggs, a total of nine eggs was found to be 'trapped' within apparently normal ruptured follicles. In addition, one corpus luteum, judged to be 1.5 days old, was found to co-exist with a number of more recent ruptured follicles (Table 3).

Table 3 shows the sum (marked B) of all the follicles that did rupture (including those with a 'trapped' oocyte) and follicles that might perhaps have done so had autopsy been delayed by a few hours. The differences in the value of ' $B$ ' between irradiated and non-irradiated ovaries then become relatively small, whereas that between air-exposed and untouched ovaries remains much the same as for ' $A$ ' (Table 3 ). The mean total values of ' $B$ ' are again highest for Treatment I (13.70), intermediate for Treatment II (13.37) and lowest for the unirradiated controls $(12 \cdot 13)$.

Ten animals (all unilaterally irradiated) failed to ovulate before autopsy. The numbers of pre-ovulatory follicles were not consistently higher on the irradiated than on the unirradiated side (Table 4). Similarly, in the five animals killed at metoestrus, the numbers of corpora lutea were higher on the irradiated side in three, and lower in the other two (Table 4). The numbers of animals are too small for valid comparisons to be made with those, receiving similar treatments, that ovulated before autopsy. In general, the mean total numbers of preovulatory follicles and corpora lutea were of the same order as those for ruptured follicles in corresponding groups (cf. Tables 3 and 4). The only apparent exception is the mean total of 15.0 pre-ovulatory follicles for Treatment $I$. All these animals were killed between $11.30 \mathrm{a} . \mathrm{m}$. and $12.20 \mathrm{p} . \mathrm{m}$. In contrast, three of the four animals receiving Treatment II (mean 13.0 pre-ovulatory follicles) were killed between 5.0 and 5.15 p.m. If the normal relationship between ovulation and the onset of darkness (see Mandl, 1963b) was not upset, pre-ovulatory changes in the nucleus would not be expected before 4 p.m. It is therefore possible that some oocytes destined to become atretic before the onset of maturation changes have been included. Previous experience (Mandl, 1963b) indicates that the numbers of pre-ovulatory follicles classified as normal is higher before (mean for seven rats: $14 \cdot 3$ ) than after the onset of maturation changes (mean for fifteen rats: 12.67). The numbers of follicles that actually ovulate appear to be slightly lower still (Text-fig. 3 ).

Size of freshly-formed corpora lutea and pre-ovulatory follicles. The freshly-formed corpora lutea in irradiated ovaries were considerably smaller than those in their non-irradiated fellows. The differences between each pair were statistically significant (Table 5). Irradiated ovaries contained more corpora lutea measuring 
less than $120 \times 10^{-3} \mathrm{~mm}^{3}$, and fewer exceeding $200 \times 10^{-3} \mathrm{~mm}^{3}$. The numbers of intermediate size, and the frequency of their occurrence, were relatively evenly distributed (Table 5).

The difference in size may be due to two factors: first, radiation-induced damage to the granulosa cells of growing follicles, as a result of which the follicles failed to reach their normal pre-ovulatory size; and second, the treatment may induce the rupture of smaller, possibly atretic, follicles which would not normally ovulate. The animals were killed before luteinization of the granulosa cells had set in. It is therefore unnecessary to consider a possible reduction in the ability of irradiated granulosa cells to undergo normal luteinization. Indeed, a comparison between the size of corpora lutea aged about 0.5 and 1.5 days in irradiated and non-irradiated ovaries indicates that the increase was of the same order in both $(213 \%$ in irradiated; $195 \%$ in non-irradiated).

TABLE 4

NUMBERS AND SIZE OF PRE-OVULATORY FOLLICLES AND CORPORA LUTEA (AGED ABOUT 1.5 DAYS) AFTER UNILATERAL IRRADIATION WITH $157 \mathrm{r}$

\begin{tabular}{|c|c|c|c|c|}
\hline & \multicolumn{2}{|c|}{ Pre-ovulatory follicles } & \multicolumn{2}{|c|}{ Corpora lutea aged about 1.5 days } \\
\hline & Mean No. & Mean diameter $(\mu m)$ & Mean No. & Mean vol. $\left(\times 10^{-3} \mathrm{~mm}^{3}\right)$ \\
\hline $\begin{array}{l}\text { Treatment I } \\
\text { Irradiated ovary } \\
\text { Ovary exposed to air } \\
\text { Both ovaries }\end{array}$ & $\begin{array}{l}7 \cdot 33 \\
7.67 \\
15 \cdot 0 \quad(6)\end{array}$ & $\begin{array}{l}624 \\
674 \\
649(6)\end{array}$ & $\begin{array}{l}6 \cdot 33 \\
7 \cdot 00 \\
13 \cdot 3 \quad(3)\end{array}$ & $\begin{array}{l}269 \\
308 \\
289(3)\end{array}$ \\
\hline $\begin{array}{l}\text { Treatment II } \\
\text { Irradiated ovary } \\
\text { Ovary unexposed } \\
\text { Both ovaries }\end{array}$ & $\begin{array}{l}6.75 \\
6 \cdot 25 \\
13 \cdot 0 \quad(4)\end{array}$ & $\begin{array}{l}606 \\
649 \\
627(4)\end{array}$ & $\begin{array}{l}10 \cdot 00 \\
3 \cdot 00 \\
13 \cdot 0 \quad(2)\end{array}$ & $\begin{array}{l}302 \\
348 \\
312(2)\end{array}$ \\
\hline
\end{tabular}

The figures in parentheses indicate the numbers of rats used.

In general, the volume of freshly-formed corpora lutea is equivalent to that of pre-ovulatory follicles. The mean volume of seventy-one pre-ovulatory follicles in irradiated ovaries (Treatments I and II; Table 4) is $125.4 \times 10^{-3} \mathrm{~mm}^{3}$. The corresponding mean for 354 newly-formed corpora lutea in irradiated ovaries is $134.0 \times 10^{-3} \mathrm{~mm}^{3}$. The equivalent values for air-exposed and untouched ovaries are: mean for seventy-one pre-ovulatory follicles, $156.2 \times 10^{-3} \mathrm{~mm}^{3}$; that for 326 newly-formed corpora lutea, $162.3 \times 10^{-3} \mathrm{~mm}^{3}$. The distribution of sizes also shows fair agreement (Text-fig. 4).

These observations suggest that the small size of freshly-formed corpora lutea in irradiated ovaries is due to radiation-induced damage to the granulosa cells of growing follicles.

Condition of tubal eggs in animals that did not mate. Serial sections of the Fallopian tubes were available for twenty-seven animals that did not mate. A total of 343 tubal eggs was examined. One or more serial sections through the nucleus of each of twelve eggs were damaged or missing; these eggs could therefore not be classified with confidence as normal or abnormal. Of the remaining 331,317 were judged to be normal oocytes at second metaphase. The remaining fourteen were considered to be somewhat unusual in appearance. It should be noted, 


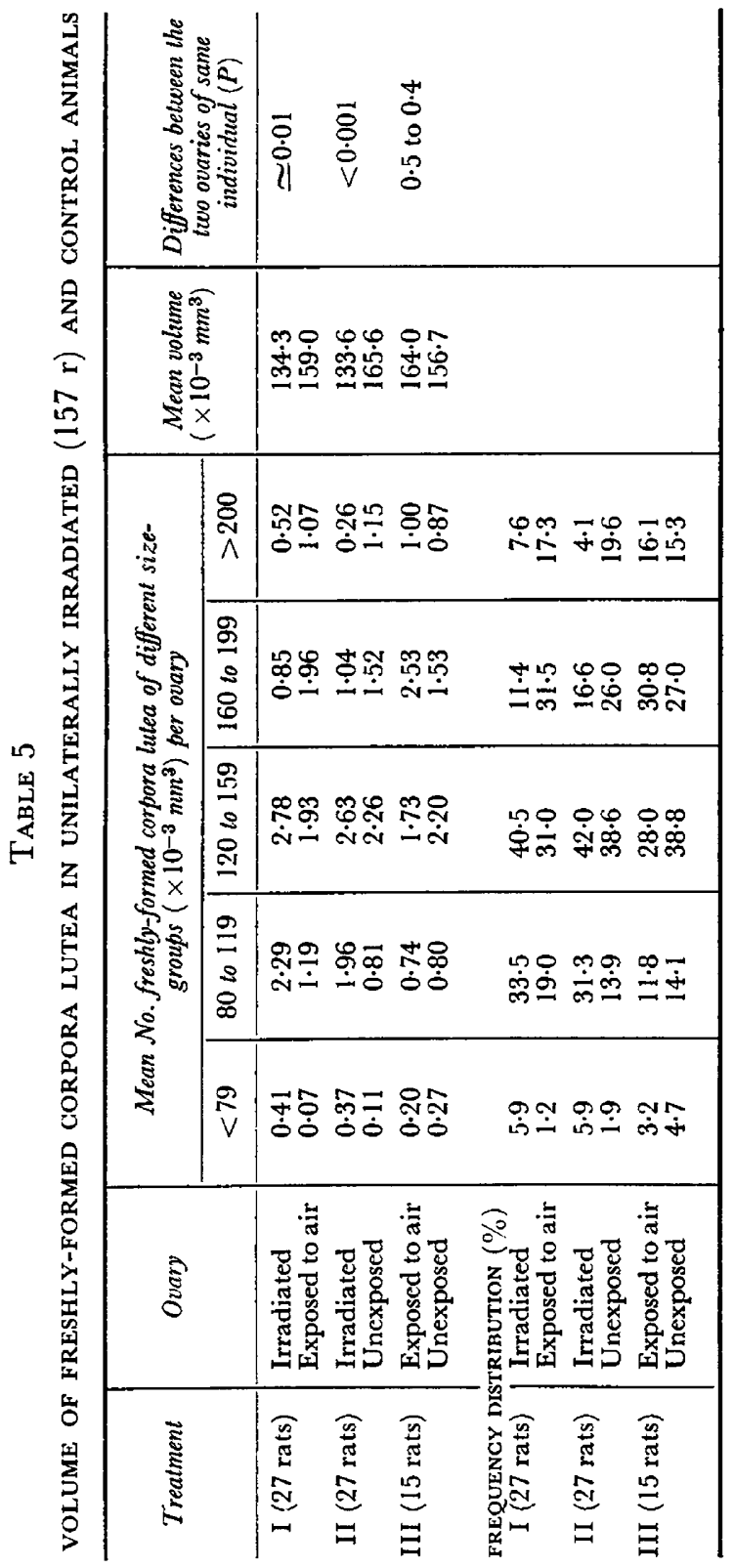


however, that it is difficult to assess the abnormality of chromosomes at second metaphase when they are cut transversely or obliquely in relation to the axis of the spindle. Moreover, the degree to which fixation may induce an apparent dispersion of the cumulus cells is difficult to estimate.

TABLE 6

GONDITION OF TUBAL EGGS AFTER MATING

\begin{tabular}{|c|c|c|c|c|c|c|}
\hline & \multicolumn{2}{|c|}{ Treatment $I$ (12 rats $)$} & \multicolumn{2}{|c|}{ Treatment II (11 rats) } & \multicolumn{2}{|c|}{ Treatment III (11 rats) } \\
\hline & \begin{tabular}{|l|} 
Irradiated \\
side $(157 \mathrm{r})$
\end{tabular} & $\begin{array}{l}\text { Air-exposed } \\
\text { side }\end{array}$ & $\begin{array}{l}\text { Irradiated } \\
\text { side }(157 r)\end{array}$ & $\begin{array}{l}\text { Unexposed } \\
\text { side }\end{array}$ & $\begin{array}{l}\text { Air-exposed } \\
\text { side }\end{array}$ & $\begin{array}{l}\text { Unexposed } \\
\text { side }\end{array}$ \\
\hline $\begin{array}{l}\text { Total No. eggs shed (as } \\
\text { judged by counts of cor- } \\
\text { pora lutea) }\end{array}$ & 71 & 83 & 82 & 64 & 69 & 64 \\
\hline No. located in Fallopian & 70 & & 81 & & \multirow{2}{*}{$58^{*}$} & \\
\hline $\begin{array}{l}\text { tube (A) } \\
\text { Proportion of (A) not fer- }\end{array}$ & \multirow[b]{2}{*}{24} & 83 & 81 & 64 & & 64 \\
\hline tilized (\%) & & 6 & 21 & 19 & 0 & 5 \\
\hline $\begin{array}{l}\text { Proportion of (A) snowing } \\
\text { abnormality }(\%)\end{array}$ & 4 & 0 & 0 & 0 & 0 & 0 \\
\hline $\begin{array}{l}\text { Normal fertilized eggs: } \\
\text { showing pronuclei (\%) }\end{array}$ & 58 & 44 & 45 & 40 & 69 & 64 \\
\hline $\begin{array}{l}\text { and condensed female } \\
\text { chromatin }(\%)\end{array}$ & 42 & 56 & 55 & 60 & 31 & 36 \\
\hline $\begin{array}{l}\text { Means for both ovaries: } \\
\text { No. normal fertilized eggs }\end{array}$ & \multicolumn{2}{|c|}{$10 \cdot 7$} & \multicolumn{2}{|c|}{$10 \cdot \tilde{z}$} & \multicolumn{2}{|c|}{$10 \cdot 8$} \\
\hline pian tube $(\%)$ & \multicolumn{2}{|c|}{83} & \multicolumn{2}{|c|}{80} & \multicolumn{2}{|c|}{98} \\
\hline $\begin{array}{l}\text { lertiluzed eggs showing } \\
\text { pronuclei }(\%)\end{array}$ & \multicolumn{2}{|l|}{49} & \multicolumn{2}{|c|}{43} & \multicolumn{2}{|c|}{66} \\
\hline $\begin{array}{l}\text { Mean time of day when } \\
\text { animals were killed }\end{array}$ & \multicolumn{2}{|c|}{11.30 a.m. } & \multicolumn{2}{|c|}{11.45 a.m. } & \multicolumn{2}{|c|}{11.55 a.m. } \\
\hline
\end{tabular}

* This large discrepancy is mainly due to no eggs being found in the left Fallopian tube of one rat whose left ovary contained nine freshly-formed corpora lutea. The right ovary contained three freshlyformed corpora, and three normal fertilized eggs were found in the tube.

The incidence of eggs judged to be abnormal was higher on the irradiated $(12 / 157)$ than on the unirradiated side (2/174). The diagnoses were made on coded slides, so that the observer was unaware of the treatment to which the specimen had been subjected.

EXPLANATION OF PLATE 1

All Figs. at $\times 1320$

Frg. 1. Transverse section through oocyte at second metaphase, showing isolated chromosome or fragment (irradiated with $157 \mathrm{r}$ ).

Frg. 2. Longitudinal section through oocyte at second metaphase, showing somewhat isolated chromosome or fragment (irradiated with $157 \mathrm{r}$ ).

FIG. 3. Longitudinal section through normal oocyte at second metaphase, showing regular congression of chromosomes on the spindle.

FIG. 4. Transverse section through normal oocyte at second metaphase.

FIG. 5. Newly fertilized egg showing sperm head within ooplasm; the female chromatin is not cut through (see Fig. 6).

FIG. 6. Newly fertilized egg at second telophase, showing extrusion of second polar body and condensation of female chromatin. Only a small portion of the male chromatin is cut through.

Frg. 7. Normal zygote showing two pronuclei.

FIG. 8. Unfertilized egg recovered from irradiated side $(157 \mathrm{r})$, showing bizarre distension of the spindle and chromosomal fragmentation. 
PLATE I

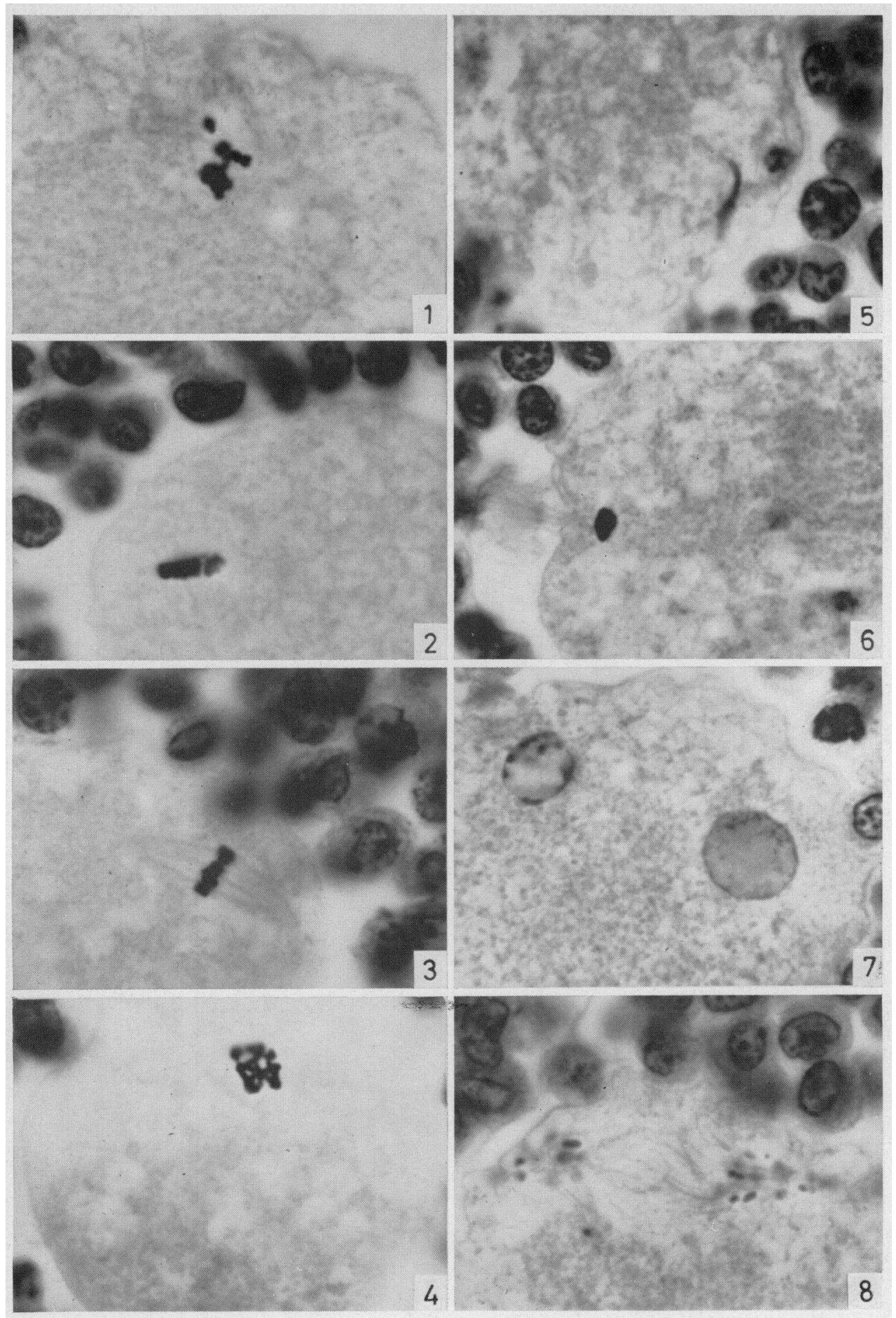

(Facing p. 388) 
Of the twelve eggs classified as abnormal on the irradiated side, three contained an isolated chromosome or fragment, the rest of the chromosomes being close together (Pl. 1, Figs. 1 and 2). The remaining nine showed degenerative changes, either in the egg or the surrounding corona; in the most severe case, only a tiny blob of cytoplasm in the centre of the cumulus persisted. The two eggs classified as abnormal on the unirradiated side both lacked a typical cumulus. One of these was situated in the ovarian bursa and not the Fallopian tube.

Condition of tubal eggs in animals that mated. Serial sections through the Fallopian tubes of thirty-four animals were searched, and 420 eggs located (thirteen fewer than expected from counts of freshly-formed corpora lutea; Table 6).

Each egg was traced through serial sections before it was classified as unfertilized (metaphase II; Pl. 1, Figs. 3 and 4) or fertilized. In the latter case, it was recorded as (i) showing an elongated or rounded sperm head, and condensed female chromatin, commonly at telophase II (Pl. 1, Figs. 5 and 6); or (ii) containing two distinct, relatively large, pronuclei (Pl. 1, Fig. 7). Eggs containing two tiny condensed masses of chromatin, presumably one of each sex, were classified as (i).

The proportion of eggs that failed to become fertilized was higher on the irradiated than on the unirradiated side, the difference being particularly marked in Treatment I (Table 6). Even so, many more eggs were unfertilized on the unirradiated side of unilaterally irradiated animals (mean $11.6 \%$ ) than in the controls $(6 \%$; Table 6$)$. The total numbers of normal fertilized eggs per rat were strikingly similar between the three treatment-groups $(10 \cdot 7,10.5$ and $10 \cdot 8$, respectively; Table 6 ).

Three of the 420 eggs were judged to be morphologically abnormal; all were unfertilized, and located on the irradiated side (Table 6). Two were only partially enclosed by a defective corona, while the third showed a bizarre spindle and dispersed chromatin (Pl. 1, Fig. 8).

The proportion of fertilized eggs that reached stage (ii) of pronuclear formation was a little higher on the irradiated than on the unirradiated side, but lower than in the non-irradiated controls (Table 6).

\section{DISGUSSION}

The present results indicate that unilateral irradiation with 630 or $315 \mathrm{r}$ induced superovulation on the unirradiated side, the number of eggs shed by the irradiated ovary being within or below the normal range. In contrast, in animals unilaterally irradiated with $157 \mathrm{r}$, the number of ovulations was a little higher on the irradiated side, irrespective of whether the other ovary was exposed to air or left untouched. The difference between the two sides was not significant statistically, but it was matched by a discrepancy of the same magnitude between the air-exposed and untouched ovary of the controls. Moreover, the number of eggs shed by the unirradiated ovary was a little higher than the mean for normal animals of the same strain; the difference was more marked if the unirradiated ovary was exposed to air.

These observations raise several problems, relating not only to the direct effects of X-rays on the ovary, but also to mechanisms mediating compensatory hypertrophy following unilateral ovariectomy. 
SUPEROVULATION FOLLOWING EXPOSURE TO DIFFERENT DOSES OF X-RAYS

The finding that unilateral exposure to 315 or $630 \mathrm{r}$ is followed by compensatory overactivity of the unirradiated ovary accords with Pozhidaev's (1960) report on rats treated unilaterally with $600 \mathrm{r}$. A similar conclusion emerges from Krehbiel \& Plagge's (1963) study of rats given localized treatment with $800 \mathrm{r}$; the effect was judged by the total number of implantation sites-a less satisfactory criterion in that pre-implantation death is likely to be higher on the irradiated side. Harvey \& Chang (1963) irradiated one ovary of adult hamsters with $200 \mathrm{r}$ at different times $(-81$ to $+8 \mathrm{hr})$ in relation to the onset of heat. Corpora lutea of pregnancy were more numerous on the unirradiated side in seven of the eight groups, the difference being particularly marked in those irradiated earliest.

The total number of eggs shed by rats exposed unilaterally to 630 or $315 \mathrm{r}$ was only a little higher than the mean for unirradiated animals of the same strain. Bilateral exposure to the same doses, on the other hand, has been shown to induce more pronounced superovulation (see Mandl, 1963a; cf. Pozhidaev, 1960; Hahn \& Morales, 1964). It would thus appear that irradiation of one ovary may be followed by some stimulus to the pituitary (presumably via the hypothalamus), and that the stimulus is stronger if both ovaries are irradiated. If one ovary is exposed to $315 \mathrm{r}$ or more (perhaps less in the hamster), it is in some way hampered in competing for gonadotrophin, as a result of which its unirradiated fellow takes up more than the usual half-share (see Falconer et al., 1961).

Unilateral exposure to $157 \mathrm{r}$ does not appear to handicap the treated ovary in this manner. Moreover, since exposure of one ovary to air (involving handling during surgery) exerts much the same effect as does low-level irradiation, the effect is seemingly non-specific. The latter conclusion is corroborated by a previous finding that unilateral hysterectomy (again involving surgical handling of the ovary) results in an increase in ovarian weight on the operated side (Mandl \& Zuckerman, 1951). The increase occurred only if oestrus intervened between operation and autopsy. There is reason to believe that it is correlated with the presence of larger numbers of corpora lutea (e.g. Arai, 1920) and hence with superovulation.

The observation that the total number of eggs shed by the unirradiated ovary was also slightly raised likewise accords with that on unilaterally hysterectomized animals. The ovary on the unoperated side also enlarged; its weight was about $20 \%$ higher, as compared with controls, at 6 to 7 days after operation, and subsequently decreased (Mandl \& Zuckerman, 1951). Further evidence that nonspecific damage to one or both ovaries leads to a transient ovarian enlargement (and presumably, rise in number of corpora lutea) is provided by Fazekas (1949) and Aron \& Marescaux (1948). Fazekas injected rabbits with various toxic substances and observed a subsequent increase in ovarian weight. Aron \& Marescaux reported that, in the guinea-pig, removal of tiny fragments of ovarian tissue or intra-ovarian injection of saline was followed by bilateral ovarian overactivity which they likened to compensatory hypertrophy after unilateral ovariectomy. The effect lasted on an average no more than 10 days.

Two conclusions emerge. First, the degree of superovulation, after bilateral irradiation, depends both on the dose of X-rays (Mandl, 1963a) and on the 
interval between irradiation and ovulation (Hahn \& Morales, 1964). Exposure to $400 \mathrm{r}$ at metoestrus induces a doubling of the number of eggs shed, the effect declining as the time of ovulation approaches (Hahn \& Morales, 1964). It has not been established whether higher or lower doses, given at metoestrus, could elicit even greater superovulation; but the available evidence suggests that the effect decreases as the dose of X-rays is raised from 315 to $630 \mathrm{r}$ and beyond (Mandl, 1963a).* It would thus appear that the ovarian stimulation elicited by irradiation rises with the dose administered, but that beyond a certain level radiation-induced damage to the follicular system counteracts the superovulatory effect.

Second, the balance between the two ovaries following unilateral irradiation is largely dependent upon the dose of X-rays. The fact that superovulation occurs in both ovaries after bilateral exposure to $315 \mathrm{r}$ (Mandl, 1963a) precludes the possibility that normal ovarian function is impaired as a result of damage to vascular or other tissues. Indeed, irradiation is usually followed by a transient hyperaemia, which may account for the slightly larger numbers of ova shed by ovaries irradiated with lower doses. It is possible that handling of the ovary during air-exposure or unilateral hysterectomy also induces a temporarily increased blood-flow through the ovary, without at the same time damaging the follicular apparatus.

Before the present observations can be discussed further, it is necessary to reexamine the problem of compensatory hypertrophy after unilateral ovariectomy.

FAGTORS CONTROLLING COMPENSATORY HYPERTROPHY AFTER UNILATERAL OVARIECTOMY

In the hamster, the degree of compensatory hypertrophy depends upon the stage of the oestrous cycle when one ovary is removed (Greenwald, 1962a, b). The optimal stage is associated with peak numbers of normal Graafian follicles which decline, due to spontaneous atresia, as ovulation approaches. Following unilateral avariectomy, the degree of spontaneous atresia is much diminished; follicles which would normally degenerate are thus able to ovulate. The same applies to the rabbit (Desaive, 1949) and the sow (Brinkley, Wickersham, First \& Casida, 1964) though not the guinea-pig (Hermreck \& Greenwald, 1964).

Degeneration of Graafian follicles in the hamster can also be inhibited by exogenous gonadotrophin, the efficacy of the treatment again depending on the stage of the cycle at which it is administered (Greenwald, 1962a). This observation suggests that the level of gonadotrophin in the normal animal is inadequate for the maintenance of all Graafian follicles present, the time when some begin to undergo atresia perhaps coinciding with a drop in the secretion of FSH. The latter view is borne out by the recent observations of Gans, de Jongh, van Rees, van der Werff ten Bosch \& Wolthuis (1964). Compensatory hypertrophy may thus result from an inhibition of this cyclical fall in FSH; or it may be mediated by a sudden rise in FSH-secretion, triggered by a drop in the level of ovarian hormones due to unilateral ovariectomy. McLaren's (1963b) relatively crude assays of total gonadotrophin in unilaterally spayed mice revealed no significant

\footnotetext{
* The ovarian dose in the experiment of Hahn \& Morales (1964) may have been below $400 \mathrm{r}$; the latter was probably the calculated whole-body (skin) dose.
} 
rise in hypophysial potency at a time when the remaining ovary was already shedding almost twice the normal number of eggs. She therefore postulated that compensatory hypertrophy may be mediated by a prolongation of the "duration of FSH stimulation". It is clear that more refined assays (e.g. Parlow, 1964) will need to be performed before either of these possibilities is proven.

\section{MECHANISMS UNDERLYING RADIATION-INDUCED SUPEROVULATION}

Greenwald's (1962a, b) observations on the degree of superovulation following unilateral ovariectomy or treatment with gonadotrophin at different stages of the cycle are strikingly parallel to those of Hahn \& Morales (1964) on irradiated rats. It seems possible, therefore, that ovarian irradiation (within certain limits of dosage) also somehow reduces the rate of spontaneous atresia, at least in adult animals (cf. immature: Sladić-Simić et al., 1963). Further evidence favouring this view derives from the following facts: (1) The total number of Graafian follicles in irradiated animals killed before ovulation does not exceed that normally present. This disposes of the possibility that irradiation induces the growth and maturation of smaller follicles 'in reserve' (see Greenwald, 1962a, b, 1963). Even in the rats showing the highest degree of radiation-induced superovulation hitherto reported (Hahn \& Morales, 1964), the number of eggs shed did not exceed that of large follicles (over $250 \mu$ in diameter) likely to have existed at the time of irradiation (cf. Mandl \& Zuckerman, 1952). (2) Rats exposed to ovarian irradiation within $24 \mathrm{hr}$ of expected ovulation showed a detectable degree of superovulation (Mandl, 1963a; Hahn \& Morales, 1964). Yet this period of the cycle is normally associated with a depletion in the number of Graafian follicles due to atresia (Mandl \& Zuckerman, 1952; Greenwald, 1962a), and the time available for further follicular growth is limited.

If it is true that irradiation causes a reduction in spontaneous atresia, then unilateral exposure to 315 or $630 \mathrm{r}$ seemingly exerts this effect only upon the unirradiated ovary. Exposure to these doses does not, however, interfere with the maturation of excessive numbers of follicles either in bilaterally irradiated or unilaterally ovariectomized animals (see Mandl, 1963a). It must be concluded, therefore, that it is only in the presence of an undamaged ovary that irradiation diminishes the chances of the treated ovary to compete on equal terms for gonadotrophin.

In animals that ovulated after unilateral irradiation with $157 \mathrm{r}$, the incidence of large unruptured follicles in air-exposed and untouched ovaries was higher, and that of freshly-formed corpora lutea lower, than on the irradiated side (Table 3). Moreover, a comparison between the numbers of pre-ovulatory follicles (in animals killed before ovulation) and the numbers of freshly-formed corpora lutea (after ovulation) shows that the discrepancy between the two is $48 \%$ greater on the air-exposed and untouched side than on the irradiated side (Text-fig. 4). In both instances, differences between the numbers of preovulatory follicles and new corpora lutea were greatest at the mode for the volume of pre-ovulatory follicles. This finding suggests that some apparently normal pre-ovulatory follicles fail to rupture, the proportion being relatively higher on the air-exposed or untouched than on the irradiated side.

The present results also show that some of the follicles that ruptured after 
unilateral irradiation with $157 \mathrm{r}$ may have been at early stages of atresia, and while capable of undergoing maturation division, were not functionally normal. The percentage of unfertilized eggs on the unirradiated side was higher than the mean of $2.7 \%$ for normal animals of the same strain (see Mandl, 1963a). This increase, unlike that reported by Hahn \& Morales (1964) for the proportion of eggs failing to implant, could not have been due to radiation-induced damage in the eggs.

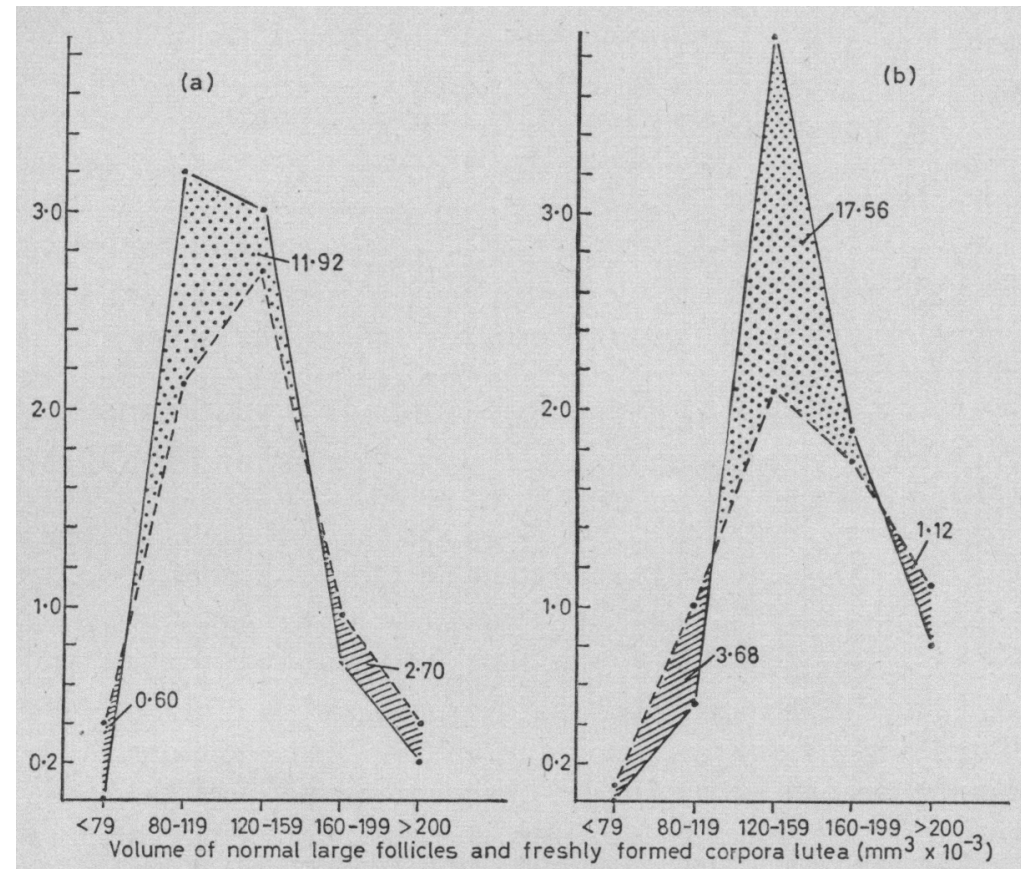

Text-Fig. 4. Frequency distribution of different size-groups of pre-ovulatory follicles $(-\ldots)$ and freshly-formed corpora lutea (. . . . -) in (a) unilaterally irradiated ovaries (pooled data for Treatment-groups I and II) and (b) air-exposed or untouched ovaries (pooled data for all three treatment-groups). Overlapping areas are stippled (excess of pre-ovulatory follicles over corpora lutea) or cross-hatched (excess corpora lutea over pre-ovulatory follicles). The figures indicate the areas in $\mathrm{cm}^{2}$, measured by means of a planimeter prior to reduction for publication.

If it is FSH that reduces spontaneous atresia of Graafian follicles, how does irradiation - or non-specific ovarian damage-alter its secretion and/or release? It is unlikely that these procedures are followed by an appreciable decrease in the level of circulating oestrogens, such as would occur after unilateral ovariectomy. There is some evidence that the nervous system may be involved in transient ovarian hyperactivity in the guinea-pig (Aron, Marx \& Marescaux, 1948a, b). Similar studies have not been performed on the rat. It is possible-though unproven - that a nervous 'impulse' emanates from the site of injury and inhibits the brief cyclical decline in the release of FsH at pro-oestrus. It also seems probable that the effect of irradiation is non-specific, and that the mechanism mediating superovulation in irradiated rats is essentially similar to that operating after unilateral ovariectomy. 
THE EFFECT OF IRRADIATION ON THE MORPHOLOGY OF TUBAL EGGS

Following unilateral exposure to $157 \mathrm{r}$, the incidence of morphologically abnormal eggs (fertilized or unfertilized) was very low. This finding is entirely in keeping with that of Harvey \& Chang (1963) on hamsters, and with previous observations on the high radio-resistance of growing follicles exposed $15 \mathrm{hr}$ or more before expected ovulation (Mandl, 1963a). Nonetheless, it is possible that had the animals been killed at a later time after mating (e.g. $36 \mathrm{hr}$ ), cleaved eggs with micronuclei might have been detected (see Harvey \& Chang, 1963). The observation that a few unfertilized eggs were surrounded by an incomplete corona suggests that they may have been shed prematurely, and had 'aged' in the oviduct (see Yanagimachi \& Chang, 1961).

By the time of autopsy, pronuclear development had not proceeded as far in unilaterally irradiated as in non-irradiated controls; yet the animals were killed at about the same time of day, on an average 9 to $10 \mathrm{hr}$ after expected ovulation (cf. Mandl, 1963b). Since only one ovary was irradiated, with a relatively low dose, it is unlikely that the hormonal milieu was sufficiently altered to affect either ovum transport or capacitation of spermatozoa. It seems more probable, therefore, that ovulation was somewhat delayed. The results also show that unilateral irradiation interferes with the usually close developmental synchronization between maturing follicles in the two ovaries (see Odor, 1955; Mandl, 1963b). The observation that slightly more eggs reached the pronuclear stage on the irradiated than on the unirradiated side of the same rat suggests that ovulation was delayed even more on the unirradiated side. The same conclusion emerged from the histological studies of the ovaries. In contrast, Harvey \& Chang (1963) recorded that the maturation division is delayed on the irradiated side in hamsters exposed at, or $3 \mathrm{hr}$ before, the onset of heat. The discrepancy between these two sets of observations may well be due to the difference in time, with respect to ovulation, at which the animals were unilaterally irradiated.

\section{ACKNOWLEDGMENTS}

The expenses incurred in this study were defrayed from grants, made to Professor Sir Solly Zuckerman, F.R.s., by the Population Council, Inc. and by the Medical Research Council.

I am indebted to Professor P. L. Krohn, F.R.s., for his helpful criticisms.

\section{REFERENCES}

ARAI, H. (1920) On the cause of the hypertrophy of the surviving ovary after semispaying (albino rat) and the number of ova in it. Amer. F. Anat. 28, 59.

Aron, C. \& Marescaux, J. (1948) Facteurs de l'hyperactivité réactionnelle de l'ovaire restant après hemicastration chez le cobaye. C.R. Soc. Biol., Paris, 142, 1009.

Aron, C., Marx, C. H. \& Marescaux, J. (1948a) Influence de la section de la moelle épinière sur l'hyperactivité réactionnelle de l'ovaire après hemicastration chez le cobaye.C.R. Soc. Biol., Paris, 142, 1556.

Aron, C., Marx, C. H. \& Marescaux, J. (1948b) Caractère réflexe, neuro-endocrinien, de l'hyperactivité réactionnelle de l'ovaire restant après hemicastration chez le cobaye. C.R. Soc. Biol., Paris, 142, 1558.

Asherman, J. G. (1952) X-ray therapy of sterility. Gynaecologia, Basel, 133, 65.

Beaumont, H. M. (1962a) The onset of puberty after X-irradiation. F. Endocrin. 24, 113. 
Beaumont, H. M. (1962b) Effect of irradiation during foetal life on the subsequent structure and secretory activity of the gonads. F. Endocrin. 24, 325.

Brinkley, H. J., Wickersham, E. W., First, N. L. \& CAsida, L. E. (1964) Effect of unilateral ovariectomy on the structure and function of the corpora lutea of the pig. Endocrinology, 74, 462.

Bruzzone, S., Lipschutz, A. \& Niedmann, L. (1952) The ovarian control of the hypophysial gonadotrophic function. 7. Endocrin. 8, 187.

Caballero, A. \& Hurtado, E. (1963) La radiothérapie hypophysaire et ovarienne chez la femme. Rev. franç. Gynéc. 58, 289.

Desaive, P. (1949) Etude des processus compensateurs de l'appareil folliculaire dans l'ovaire de lapine adulte. Arch. Biol., Paris, 60, 137.

Falconer, D. S., Edwards, R. G., Fowler, R. E. \& Roberts, R. C. (1961) Analysis of differences in the numbers of eggs shed by the two ovaries of mice during natural oestrus or after superovulation. F. Reprod. Fertil. 2, 418.

FAZEKAs, I. G. (1949) Experimental data for influencing ovarial function with simple compounds (transl.). Orv. Hetil. 90, 777. (Cited in Excerpta med., Amst. (1950) 4, Abstr. No. 760, p. 192.)

Fraenkel, M. (1914) Die Reizwirkung der Röntgenstrahlen und ihre therapeutische Verwendung. I. Bei Chlorose. Zbl. Gynäk. 38, 932.

Fullenlove, T. M., Haman, J. O. \& Williams, A. J. (1956) Roentgen therapy in anovulation and sterility. Fertil. Steril. 7, 18.

Gans, E., De Jongh, S. E., van Rees, G. P., van der Werff ten Bosch, J. J. \& Wolthuis, O. L. (1964) Cyclic variation in the hypophyseal FSH-content in the female rat. Acta endocr., Kbh., 45, 335.

GreENWALD, G. S. (1962a) Analysis of superovulation in the adult hamster. Endocrinology, 71, 378.

GREENWALD, G. S. (1962b) Temporal relationship between unilateral ovariectomy and the ovulatory response of the remaining ovary. Endocrinology, 71, 664 .

GREENWALD, G. S. (1963) Effect of anti-PMS serum on superovulation in the hamster. Endocrinology, 73, 436.

Hahn, E. W. \& Morales, R. L. (1964) Superpregnancy following pre-fertilization X-irradiation of the rat. J. Reprod. Fertil. 7, 73.

Harvey, E. B. \& Chang, M. C. (1963) Effects of X-irradiation of ovarian ova on the morphology of fertilized ova and development of embryos. F. cell. comp. Physiol. 61, 133.

Hermreck, A. S. \& Greenwald, G. S. (1964) The effects of unilateral ovariectomy on follicular maturation in the guinea pig. Anat. Rec. 148, 171.

KAPLAN, I. I. (1948) The use of high voltage roentgen therapy in the treatment of amenorrhea and sterility in women. Amer. F. Roentgenol. 59, 370.

KapLAN, I. I. (1958) The treatment of female sterility with X-ray therapy directed to the pituitary and ovaries. Amer. F. Obstet. Gynec. 76, 447.

Krehbiel, R. H. \& Plagge, J. C. (1963) Number of rat ova implanting after sub-sterilizing X-irradiation of one or both ovaries. Anat. Rec. 146, 257.

Lacassagne, A., Duplan, J. F., Marcovich, H. \& Raynaud, A. (1962) The action of ionizing radiations on the mammalian ovary. The Ovary, vol. II, chap. 22. Eds. S. Zuckerman, A. M. Mandl and P. Eckstein. Academic Press, London.

Mclaren, A. (1963a) The distribution of eggs and embryos between sides in the mouse. F. Endocrin. 27, 157.

McLAREN, A. (1963b) Mechanisms of ovarian compensation following unilateral ovariectomy in mice. 7. Reprod. Fertil. 6, 321.

Mandel, J. (1935) An experimental study of ovarian irradiation and transplantation in the rat. Anat. Rec. 61, 295.

Mandel, J. \& Grisewood, E. N. (1934) Ovarian irradiation and sexual precocity in the rat. Proc. Soc. exp. Biol., N.Y. 32, 155.

MandL, A. M. (1954) The sensitivity of adrenalectomized rats to gonadotrophins. F. Endocrin. 11, 359.

MANDL, A. M. (1959) A quantitative study of the sensitivity of oocytes to X-irradiation. Proc. roy. Soc. B, 150, 53 .

MANdi, A. M. (1963a) The radio-sensitivity of oocytes at different stages of maturation. Proc. roy. Soc. B, $158,119$.

MAnde, A. M. (1963b) Pre-ovulatory changes in the oocyte of the adult rat. Proc. roy. Soc. B, 158, 105.

MANDL, A. M. \& ZuCKeRMAN, S. (1951) Ovarian hypertrophy after unilateral hysterectomy. F. Endocrin. 7,339 .

Mandl, A. M. \& Zuckerman, S. (1952) Cyclical changes in the number of medium and large follicles in the adult rat ovary. 7 . Endocrin. 8, 341.

Mandr, A. M. \& ZuCKERMAN, S. (1956) The reactivity of the X-irradiated ovary of the rat. F. Endocrin. 13, 243.

Mandi, A. M. \& Zuckerman, S. (1961) X-ray sterilization of immature female rats. F. Endocrin. 23, 179.

Morgan, J. E. \& ReYes, C. T. (1957) X-ray therapy for amenorrhea and sterility. Obstet. Gynec. 9, 175. 
ODOR, D. L. (1955) The temporal relationship of the first maturation division of rat ova to the onset of heat. Amer. J. Anat. 97, 461.

PARLow, A. F. (1964) Importance of differential, quantitative bio-assays for pituitary gonadotrophins in the rat. Endocrinology, 74, 138.

Peters, H. \& Levy, E. (1963) Effect of irradiation in infancy on the fertility of female mice. Radiat. Res. 18,421 .

Pozhidaev, E. A. (1960) Excess ovulation after X-ray irradiation of rats (transl.). C.R. Acad. Sci. U.R.S.S. 131, 189.

RuBin, I. C. (1926) Sterility associated with habitual amenorrhea relieved by X-ray therapy. Amer. $\mathcal{J}$. Obstet. Gynec. 12, 76.

RUGH, R. (1964) Ionizing radiations and reproductive capacity. Effects of Ionizing Radiations on the Reproductive System, p. 25. Eds. W. D. Carlson and F. X. Gassner. Pergamon Press, Oxford.

Russell, L. B. \& Russelr, W. L. (1954) Pathways of radiation effects in the mother and embryo. Cold Spr. Harb. Symp. quant. Biol. 19, 50.

Russeld, L. B. \& RusseLr, W. L. (1956) Sensitivity of different stages in oogenesis to the radiation induction of dominant lethals and other changes in the mouse. Progress in Radiobiology, p. 187. Eds. J. S. Mitchell, B. E. Holmes and G. L. Smith. Oliver \& Boyd, London.

Sladić-Simić, D., Žıvković, N., Pavić, D. \& Martinovitch, P. N. (1963) The effects of total-body X-irradiation on the reproductive glands of infant female rats. Cellular Basis and Aetiology of Late Somatic Effects of Ionizing Radiation, p. 327. Ed. R. J. C. Harris. Academic Press, London.

Yanagimachi, R. \& Chang, M. C. (1961) Fertilizable life of golden hamster ova and their morphological changes at the time of losing fertilizability. $\mathcal{F}$. exp. Zool. 148, 185. 